\title{
Pope John Paul II in Hiroshima
}

The Pope's visit last week to non-Christian Japan showed how well this indefatigable traveller can tune his speeches to his audience. With the faithful thin on the ground, general issues took precedence over those that domestically occupy his Church. The result was a more open discussion of some perplexing problems than in the Philippines the week before. And nobody should complain that the Pope followed other statesmen to Hiroshima for a major speech on the problem of nuclear war. The melodrama of the site ensures that some notice will be taken of what is said. Not surprisingly, the Pope's discussion was a good deal more perceptive than many that have preceded it. The visit also provided him with an opportunity to pat on the back one of the two sponsors of the occasion, the United Nations University. The university's new rector, the Indonesian Soedjatmoko, seems well placed to help the university make a mark in its chosen field of interest, the development of developing countries.

The danger facing those who make speeches at Hiroshima is that of following the same hackneyed theme. Nuclear weapons are awful things, and the product of scientific research, from which it follows that the sharpest dilemma is the Promethean dilemma. The Pope fortunately had the wit to acknowledge that this task has political as well as ethical or moral dimensions. However powerful may be people's collective wish that nuclear war should not break out, their political differences ensure that the danger will remain alive. It would be asking too much to accept the argument, for which there is some justification, that only the balance of terror has kept the peace these past thirty years. But the implication of his remarks (at Nagasaki) that the United Nations must more powerfully assume a peacekeeping role is needlessly unearthly; the United Nations is a place where governments with different interests meet, as often to declare their differences as to resolve them. Although the United Nations has from time to time passed high-sounding resolutions on the need for "general and complete disarmament" (known as "GCD" in the trade) the painfully slow processes of the Committee on Disarmament shows what problems lie ahead.

Fortunately, not all problems are such inherently gloomy problems. Although the theme of the Pope's speech last week was "the ethical problems of the technological society", he reminded those who heard him that "we all greatly benefit" from the application of science and technology. In the past few gloomy years, optimism on this score seems to have melted surreptitiously away, not so much from anxiety about war as because of the faltering of the industrial economies and the predictable but nonetheless bitter failure of efforts such as the United Nations conference on technology and development two years ago. But can it be that the promise of science and technology for the improvement of the human condition, widely believed only a few years ago, has evaporated overnight? Is it not more likely that people have become discouraged? And, in these circumstances, may it not be especially valuable that vaguely incongruous figures like the Pope should go about reminding people that the promise is still there to be captured?

But how? At Hiroshima, the Pope said that the need was for a "moral about-face". Translated into the language of everyday politics, the implication is that governments must become more serious in their consideration of documents such as the report of the Brandt Commission on the problems of contemporary development, more imaginative in their management of domestic wealth and liberty and more courageous in their handling of dealings with each other. But, in the last resort, governments - even illiberal governments - are merely the products of their people. Is the practical message of what the Pope was saying last week about the moral responsibility of the scientific community that the time has come when governments should be reminded again, as they have been ad nauseam in earlier decades since the Second World War, that the time has come to start solving problems, not to be mesmerized by them?

\section{Ructions in space}

The European Space Agency is using unaccustomed undiplomatic language in its attempts to persuade the new United States Administration not to force the cancellation of the joint venture to put a pair of spacecraft into polar orbits about the Sun. Rumours that this might be one of the consequences of the cut in the budget of the National Aeronautics and Space Administration have been circulating in Washington for several days (see Nature 26 February, p.738). The European reaction to the news that the rumours are true has been understandably tetchy. Europe, the European Space Agency is saying, has been led up the garden path, has been induced to lavish a substantial part of the meagre funds available for planetary exploration on a project whose value will now be much reduced (see page 3), and which may even have to be abandoned altogether. By asking that member states should send their diplomats into action in Washington, the European Space Agency has broken new ground in the foreign relations of multilateral agencies like itself. The bad temper in its public statement on the problem suggests that good relations may be at an end.

Luckily, that time may not yet have arrived. There remains a chance that the American half of the solar polar mission will be restored in the budget to be published on 10 March. More to the point, there is every chance that the United States Congress, still not quite certain what to make of President Reagan and his wellintentioned but draconian fiscal policies, will write back into the budget some of the items the President is planning to strike out. (And then, of course, it is always possible that the White House might decide not to spend the money, anyway.) In short, it is too soon to be supposing that the solar polar experiment is a washout. What has happened is more subtle but also more important.

Domestically, the United States space programme is in a mess. For the past three years, the space shuttle, the machine intended as the launching vehicle both for commercial and scientific spacecraft, has been in trouble. It is already two years late, and further difficulties may come to light in the critical months ahead. Yet it is too late to complain that the United States should have embarked on a quite different programme of development ten years ago, when the Apollo programme ended. Willynilly, the shuttle is the only sufficiently versatile launching system in sight. If its use is further delayed, the consequences will be more serious than the cancellation of the American half of the solar polar project. The European half may be without a launcher as well, while a whole string of communications satellites will have to find their way into synchronous orbits by quite different means. Worse still, for the scientific community, the Large Space Telescope in which the European Space Agency also has a substantial stake and which the United States Administration has so far (to its credit) kept free from cuts, will also be in jeopardy. Bad temper is, in the circumstances, inappropriate.

Looking further ahead, however, the European Space Agency 